ORIGINAL ARTICLE

\title{
Study on Level of Knowledge on Climate Change Among the People Residing in a Selected Area of Dhaka City
}

\author{
*SM Hossain ${ }^{1}$, MA Tarafdar ${ }^{2}$, MA Sheikh ${ }^{3}$, S Baroi $^{4}$ \\ ${ }^{1}$ Dr. (Lt Col) Sarder Mahmud Hossain, Associate Professor, NUB, \\ ${ }^{2} \mathrm{Sk}$ Md. Alif, Senior Lecturer, NUB; ${ }^{3}$ Monowar Ahmad Tarafdar, Professor, RRMC \\ ${ }^{4}$ Dr. Supti Baroi, Sector Coordinator, Health Project, Dhaka East ADP, World Vision, Bangladesh \\ *Corresponding author
}

\begin{abstract}
A descriptive type of cross sectional study was conducted at Badda, Dhaka to assess the level of knowledge on climate change of the people with a purposive sample size of 226. Nearly half of the respondents heard about the global warming but $43.24 \%$ didn't. A major portion of the respondents (62.39\%) agreed to include the Climate Change in school curriculum. $39.38 \%$ respondents strongly agreed that the world climate is changing but it was due to human behavior which was strongly agreed by $16.81 \%$. $17.26 \%$ strongly believed that developed countries are the main contributors. $15.49 \%$ of the respondents strongly agreed that developed countries should provide compensation to the affected developing countries. Neither agreed nor disagreed that the Climate Change had impact on economy was $38.06 \%$ but $40.27 \%$ respondents strongly agreed that Climate has impact on human health. $36.73 \%$ respondents strongly agreed that Climate Change has impact on food production and $34.07 \%$ strongly agreed that it has impact on soil condition and fertility. $49.56 \%$ respondents strongly agreed for the need to take measure to reduce or prevent Climatic Change and $43.23 \%$ strongly agreed on awareness creation to cope with Climate Change. TV/RADIO was the most important source of information about global warming $(82.75 \%)$. The association between educational level and knowledge on Climate Change was found to be significant. As the climate change has already put a devastating impact on survival on millions, effective action plan to be undertaken to control the impact on environment and create awareness about the adverse effects of it on the globe.
\end{abstract}

Key words: Global Warming, Green House Effect, Climate Change, Health Impact

\section{Introduction}

Climate change is a long-term change of weather pattern over periods of time that range from decades to millions of years. Factors that can shape climate are climate forcing. These include such processes as variations in solar radiation, deviations in the earth's orbit, mountain - building and continental drift, and changes in greenhouse gas concentrations. Climate change influenced by the global warming is certainly one of the most serious threats facing the present day world. The rapid melting glaciers on the Himalayas and Arctic, among other indicators, suggest that it is no longer a distant futuristic scenario but an immediate threat ${ }^{1}$.
The climate change brought about by the global warming has posed a moral threat to the lives and livelihood of millions in Bangladesh. Recent research predicts that about 20 million people in the low-lying areas of Bangladesh are at risk from rising sea level which would trigger mass migration northwards increasing pressure on lands and resources and loss of livelihood for millions. It is worrying to know that a rise of one degree Celsius in temperature might cause as much as $15 \%$ of our land to go under water. Rainfall estimation is essential because of such consequences as flooding and drought, common natural disaster and invaluable source of renewable fresh water in Bangladesh. 
Climate change has posed a very big challenge to the South Asian countries. Bangladesh is bearing the brunt heavily of climate change and its poor people are paying the highest prices to climate stimuli. Climate change has been causing devastation on its socio-economic development as both the frequency and intensity of natural disasters like floods, cyclone, draught and tidal waves are on the rise ${ }^{2}$.

Adaptation to climate change may build the capacity of vulnerable groups of people to survive with adversities. It is likely to slow down the possible climate change or extreme climatic events while mitigation, as response strategy would reduce Green House Gas emission and thus help to stabilize rapid climate change. Adaptation deals with adverse effects of climate change through a process, practices and structure. Government and NGOs are working together to build adaptive resilience society in Bangladesh ${ }^{3}$. Bangladesh so far has not developed significant adaptation strategies to cope with climate changes. Yet people have been coping with changes through their indigenous knowledge based adaptation tools and strategies for a longtime ${ }^{4}$.

\section{Materials and Methods}

It was a descriptive type of cross-sectional study carried out from May to August 2011 with the sample size of 226 in the Badda area of Dhaka. A pre-tested, modified, semi structured, self administrated questionnaire was designed based on five point likert scale to collect the information. A purposive sampling technique was adopted. A total of 226 participants were interviewed. The respondents belonged to the age between 20 and 60 years with mean age $34.55 \pm 7.2$ years. Samples were taken from all classes, from highly educated group to day laborer, housewife to service holder. Majority of respondents belonged to age group 30-39 years ( $40.71 \%)$, followed by $20-29$ years $(27 \%)$. Of the respondents $65.05 \%$ were female, of whom $41.15 \%$ were housewife followed by service holder $17.26 \%$, laborer $11.06 \%$ and business $9.74 \%$. $31 \%$ of the respondents were educated up to the HSC level, $21 \%$ were graduate, $20 \%$ post graduate and $17 \%$ had education up to secondary level. Monthly family income of $39 \%, 18 \%$ and $35 \%$ respondents was between 20,000 to 30,000 BDT, 11,000 to 15,000 and up to 30,000 BDT respectively. $62.39 \%$ of the respondents opined to include climate change in school curriculum while $15.04 \%$ strongly agreed and $13.72 \%$ disagreed. $49.12 \%$ respondents were well aware on global warming while $30.98 \%$ did not hear about it and remaining $19.91 \%$ had no idea about global warming. Among those who were aware of global warming $36.04 \%$ had knowledge about green house effect, $43.24 \%$ had no knowledge and $20.72 \%$ never heard about it. About $40 \%$ of the respondents have the idea that to create awareness among population on climate change and global warming the best way is mass media followed by Campaign program $34.96 \%$ and Health education $25.22 \%$. Data were checked, cleaned and edited properly before entry and analysis. The data were analyzed by using the statistical software (SPSS), version 16.0 (Chicago). Descriptive statistics were used for interpretation of the finding. Associations were determined by using the Chi square test (?2) where $\mathrm{p}$-value was set 0.05 .

\section{Results}

Table 1: Distribution of respondents by their level of knowledge on climate change $(n=226)$

\begin{tabular}{|c|c|c|c|}
\hline Variables & Satisfactory & $\begin{array}{l}\text { Neither } \\
\text { Satisfactory nor } \\
\text { Not satisfactory }\end{array}$ & $\begin{array}{l}\text { Not } \\
\text { satisfactory }\end{array}$ \\
\hline World climate is changing & $158(69.91 \%)$ & $40(17.70 \%)$ & $28(12.39 \%)$ \\
\hline $\begin{array}{l}\text { Climate change is due to } \\
\text { human behavior }\end{array}$ & $112(49.55 \%)$ & $15(6.64 \%)$ & $99(43.81 \%)$ \\
\hline $\mathrm{CC}$ is a Natural occurrence & $160(70.8 \%)$ & $4(1.77 \%)$ & $62(27.44 \%)$ \\
\hline $\begin{array}{l}\text { Green house gases are } \\
\text { related to } C C\end{array}$ & $117(51.77 \%)$ & $27(11.95 \%)$ & $62(88.1 \%)$ \\
\hline $\begin{array}{l}\text { Global warming will cause } \\
\text { rise of sea level }\end{array}$ & $147(65.1 \%)$ & $32(14.16 \%)$ & $47(20.8 \%)$ \\
\hline $\begin{array}{l}\mathrm{CC} \text { is Due to ozone layer } \\
\text { destruction }\end{array}$ & $158(69.92 \%)$ & $37(16.37 \%)$ & $31(13.71 \%)$ \\
\hline $\begin{array}{l}\mathrm{CC} \text { is due to rapid } \\
\text { deforestation }\end{array}$ & $110(48.68 \%)$ & $54(23.9 \%)$ & $62(27.44 \%)$ \\
\hline $\begin{array}{l}\mathrm{CC} \text { has impact on health of } \\
\text { human being }\end{array}$ & $160(70.8 \%)$ & $33(14.6 \%)$ & $33(14.61 \%)$ \\
\hline $\begin{array}{l}\text { CC has impact on land } \\
\text { condition and soil fertility }\end{array}$ & $131(57.97 \%)$ & $34(15.04 \%)$ & $61(27 \%)$ \\
\hline $\begin{array}{l}\text { Is associated with natural } \\
\text { disaster frequency }\end{array}$ & $113(50.0 \%)$ & $98(43.36 \%)$ & $81(35.83 \%)$ \\
\hline $\begin{array}{l}\mathrm{CC} \text { has impact on food } \\
\text { production }\end{array}$ & $147(65.1 \%)$ & $40(17.7 \%)$ & $39(17.26 \%)$ \\
\hline $\begin{array}{l}\text { CC has impact on economic } \\
\text { condition }\end{array}$ & $59(26.11 \%)$ & $86(38.06 \%)$ & $81(35.85 \%)$ \\
\hline $\begin{array}{l}\text { Developed countries are the } \\
\text { main contributors in CC } \\
\text { issues }\end{array}$ & $95(42.04 \%)$ & 20 (8.85\%) & $111(49.12 \%)$ \\
\hline $\begin{array}{l}\text { Developing countries are } \\
\text { the victim for impact on CC }\end{array}$ & $143(63.27 \%)$ & $30(13.28 \%)$ & $53(23.46 \%)$ \\
\hline $\begin{array}{l}\text { Developed countries } \\
\text { should provide } \\
\text { compensation to the } \\
\text { developing countries }\end{array}$ & $100(44.25 \%)$ & $43(19.03 \%)$ & $83(36.72 \%)$ \\
\hline $\begin{array}{l}\text { Measure need to reduce or } \\
\text { prevent CC }\end{array}$ & $153(67.70 \%)$ & $57(25.22 \%)$ & $16(7.08 \%)$ \\
\hline
\end{tabular}


It is found from no. 1 that $39.38 \%$ respondents strongly agreed, $30.53 \%$ agreed, while $17.7 \%$ neither agreed nor disagreed but $7.52 \%$ disagreed and $4.87 \%$ strongly disagreed that global climate is continuously changing. On the other hand, $32.74 \%$ strongly agreed and $31.42 \%$ disagreed that Climate change is due to human behavior. $50.0 \%$ strongly agreed and $20 \%$ agreed that Climate Change is a Natural occurrence. $24.34 \%$ strongly agreed and $27.43 \%$ agreed that Green house gases are related to Climate Change while $11.95 \%$ neither agreed nor disagreed, $18.59 \%$ disagreed and $17.7 \%$ strongly disagreed on this point. On the other hand $45.58 \%$ agreed, $19.47 \%$ strongly disagreed that Global warming will cause rise of sea level. $36.73 \%$ agreed, $33.19 \%$ strongly agreed, $16.37 \%$ neither agreed nor disagreed that Climate Change is due to ozone layer destruction. $27.88 \%$ strongly agreed, $23.9 \%$ neither agreed nor disagreed, $20.8 \%$ agreed and $20.36 \%$ disagreed that Climate Change is due to rapid deforestation. $40.27 \%$ strongly agreed, $30.53 \%$ agreed, $14.6 \%$ neither agreed nor disagreed and $12.39 \%$ disagreed that Climate Change has impact on health of human being. Of the respondents $34.07 \%$ strongly agreed, $23.9 \%$ agreed, $18.59 \%$ disagreed and $15.04 \%$ neither agreed nor disagreed that Climate Change has impact on land condition and soil fertility. $29.2 \%$ respondents disagreed, $27.88 \%$ agreed, $22.12 \%$ strongly agreed, $14.16 \%$ neither agreed nor disagreed that land condition is associated with natural disaster frequency. $36.73 \%$ respondents strongly agreed, $28.32 \%$ agreed, $17.7 \%$ neither agreed nor disagreed, 9.74\% disagreed and $7.52 \%$ strongly disagreed that Climate Change has impact on food production. On the other hand $38.06 \%$ respondents neither agreed nor disagreed, $18.15 \%$ strongly disagreed, $17.7 \%$ disagreed, $13.72 \%$ strongly agreed and $12.39 \%$ agreed that Climate Change has impact on economic condition.

The table also reveals that highest $33.19 \%$ respondents disagreed, $24.78 \%$ agreed, $17.26 \%$ strongly agreed, $15.93 \%$ strongly disagreed and $8.85 \%$ neither agreed nor disagreed that
SM Hossain, MA Tarafdar, MA Sheikh et al

developed countries are the main contributors in climatic change issues. On the other hand, highest number of respondents $42.03 \%$ strongly agreed, $21.24 \%$ agreed, $13.72 \%$ strongly disagreed, $13.28 \%$ neither agreed nor disagreed and $9.74 \%$ disagreed that developing countries are the victim for impact on climate change. Study also found that $28.76 \%$ respondents agreed, $21.68 \%$ strongly disagreed, $19.03 \%$ neither agreed nor disagreed, $15.49 \%$ strongly agreed and $15.04 \%$ disagreed on the point of compensation by developed countries to the developing countries affected by global warming. Highest number respondents (49.56\%) strongly agreed, $25.22 \%$ neither agreed nor disagreed, $18.14 \%$ agreed that measures need to be undertaken to reduce or prevent climate change. On the other hand, most of the participants $(48.23 \%)$ strongly agreed, $27.44 \%$ agreed, $19.47 \%$ neither agreed nor disagreed that increase of knowledge and awareness is necessary to cope with climate change. In the current study it was revealed that there is a statistical significant association between educational status of respondents and knowledge on climate change $(P=0.000)$, impact climate change on human health $(\mathrm{P}=$ $0.000)$, measure need to reduce or prevent climate change $(\mathrm{P}=0.001)$.

\section{Discussion}

Climate change due to global warming has already hampered the normal live millions and affected the ecological balance to a great extent. Nearly half of the respondents (49.12\%) heard about the global warming. In 2007, 33\% Americans called Global Warming the "biggest environmental problem the World faces at this time." Up from $16 \%$, a year earlier 6 . In another study it was found that $63 \%$ of Americans believe that global warming is continuing. This finding was probably due to high accessibility of electronic and print media in and the issue of global warming is being widely discussed. 57\% Americans know that the greenhouse effect refers to gases in the atmosphere that traps heat. The study also revealed that beside hearing of global 
Study on Level of Knowledge on Climate Change Among

warming $43.24 \%$ did not hear about the green house effect. $24.34 \%$ strongly agreed and $27.43 \%$ agreed that green house gases are related to climate change ${ }^{5}$.

In the present study TV/Radio were the most important source of information of global warming (82.75\%). $39.82 \%$ respondents agreed that the mass media is effective for message dissemination followed by family members and neighbors $(69.02 \%)$, newspaper $49.56 \%$, poster/pamphlet $40.71 \%$ and training $16.38 \%$. Health training could be an effective source of transmission of information about global warming as it has many impacts on health though it is lacking in the study. $39.82 \%$ respondents disclosed that the mass media is effective for message dissemination. $34.96 \%$ respondents believed that organized campaign could be the effective source of information. But $25.22 \%$ agreed about that health training is the effective way. Bangladesh Bureau of Statistics reveals the fact that $62.1 \%$ population reported to listen to $\mathrm{TV} / \mathrm{radio}^{7}$. Majority of the respondents $(62.39 \%)$ agreed to include the climate change in school curriculum and $15.04 \%$ agreed strongly, disagreed $13.72 \%$. But neither agreed nor disagreed was $8.85 \%$. This finding is very close to the findings in a study in America where $75 \%$ Americans say that they should teach school children about climate change 5 .

$39.38 \%$ respondents strongly agreed and $30.55 \%$ respondents agreed that the world climate is changing. $32.74 \%$ agreed that climate change is due to human behavior whereas only $16.81 \%$ strongly agreed. But $50 \%$ of Americans understand that global warming is caused mostly by human activities which are also closer to the findings of this study. $24.34 \%$ of respondent strongly agreed and $27.43 \%$ agreed that green house gases are related to climate change. $45 \%$ Americans understand that carbon dioxide traps heat from the Earth's surface ${ }^{5}$. This finding is not similar to the finding of the present study it seems that about global warming people of this country has a better idea and information. Study of an international NGO revealed that 50\% respondents strongly agreed the climate change is a natural occurrence, $17.26 \%$ strongly agreed that developed countries are the main contributors to climate change, $15.49 \%$ strongly agreed that developed countries should give compensation to the developing countries whereas $38.06 \%$ neither agreed nor disagreed that the climate change has impact on economy. This may be due to lack of knowledge of the respondents or poor access to electronic and print media.

Present study shows that $33.19 \%$ strongly agreed and $36.73 \%$ agreed that the depletion of ozone layer is related to climate change. About $74 \%$ of prospective teachers think that holes in the ozone layer causes the green house effect found in a study in Turkey which is very close to the present finding 8 .

$40.27 \%$ strongly agreed that climate change has impact on human health, $36.73 \%$ strongly agreed that climate change has impact on food production \& $34.07 \%$ strongly agreed that it has impact on soil condition, fertility. This may be due to observation of changing seasonal pattern, increase sickness and reduced agriculture products and price hike of food products and increased frequency of disasters throughout the country during last 10 years. It could be so that other factors like over use of chemical fertilizers, use of adulterated fertilizers is also responsible substantially but it was not included in the study and definite reasons could be identified particularly for Bangladesh.

$49.56 \%$ respondents strongly agreed for the need to reduce or prevent climate change and $43.23 \%$ strongly agreed to increase knowledge and awareness is necessary to cope with climate change but how could it be achieved was not evaluated.

Association between education of respondents and knowledge on climate change and its impact on human health was significant as well as measures needed to reduce or prevent climate change was significant ( $p$-value $<0.05$ ). 


\section{Conclusion}

Global climate change is now a global concern in the developing countries like Bangladesh. The upcoming consequences are - rising sea levels, increasing salinity affecting fertility of cultivable land, depleted agriculture, reduced water flows, increased health hazards, unpredictable weather, and social strains. These suggest that both developed and developing countries have good reason to worry about climate change. Developing countries have become more vulnerable to it than developed countries and climate change will exacerbate income inequalities between and within countries, increased hunger, malnutrition, health burden and social unrest. Some environmental effects due to global warming would be irreversible; some of its societal impacts will be unmanageable. Under such circumstances global leaders should come forward with unified opinion to immediately reduce and gradually eliminate the contributing factors for global warming.

\section{References}

1. Fourth Assessment Report, IPCC [Online], [Accessed on 5/5/2011] Available from: URL:http:// www.ipcc.ch/pdf/assesement-report/ar4/wg2/ar4wg2-spm.pdf.

2. M. Feroz Ahmed, Saleh, Tanveer,Bangladesh Enviroment-2010, BAPA(Bangladesh Dhaka, Paribesh Andolon), BEN(Bangladesh Enviroment, Network) , 2010
3. Dipen Bhattacharia, M. feroze Ahmed, Nazrul Islam, Mohd. Abdul Matin Climate Change and the Tasks for Bangladesh, Dhaka, BAPA (Bangladesh Paribesh Andolon), Ben (Bangladesh Environment Network (BEN), 2009

4. Sukanta Sen, Fatema Zhura Kjhatoon, Tahmina Akhter, Shirin Akter, Mahammad Arifur Rahman, Md.. Samiur Rahman et al, editors Climate Change Impacts And Adaptation Strategies of the Indigenous Communities in Bangladesh Dhaka, BARCIK, 2009.

5. Americans knowledge of Climate Change, [Online] Anthony Leiserowitz, Nicolas Smith, Marlon, Jennifer R. [accessed 0n 24/10/11]Availablefrom-URL: http// environment.yale.edu/climate/files/climate change knowledge, 2010.pdf/

6. Ariel Malk, Jon A. Kroshric, Gary Langer, The association of knowledge with concern About Global Warming [Online]: Trusted information Sources Shape Public thinking [accessed on 16/10/11]. Available from-URL: http/sciencepolicy.colorado.edu/students

7. Bangladesh Bureau of Statistics (BBS) [Online] [Accessed on 16/10/11] Available from: URL;http//www.bbs.gov.bd./home.aspx

8. Mustafa, Hasan, Mehmet, Muhammed, Mustafa, Prospective Turkish elementary science teachers knowledge level about the green house effect and their views on environmental education in University, Electronic Journal of Elementary International Education[Online] ,2010 [accessed on 16/10/11] March 2; 2(2), 218-223. Available from: URL: http//www.jejee.com/2 